\title{
Western Faculty Profile: Dr. Elizabeth Webb
}

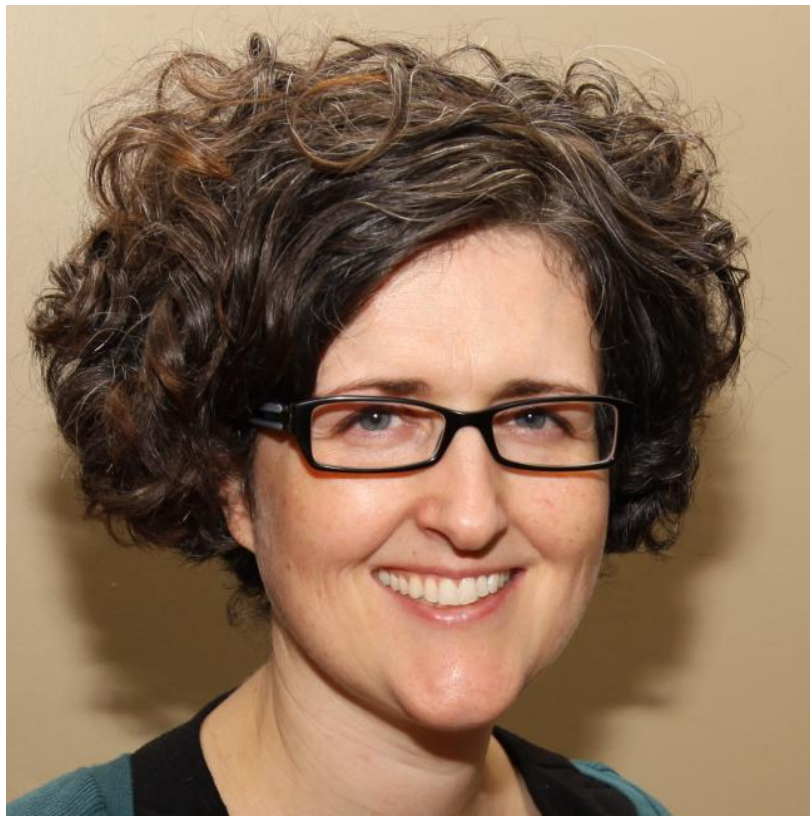

\section{Background}

Dr. Elizabeth Webb is an Associate Professor in the Department of Earth Sciences at Western University. After studying classical geology for four years, she found her true passion in stable-isotope biogeochemistry, focusing specifically on the dynamic interaction between plant mineralization and climate. Her intriguing research on Central American soils has allowed for a comprehensive understanding of climate change and ecosystem response to climate change and anthropogenic landscape modifications. Suzy Kim, a WURJHNS representative, had the wonderful opportunity to interview Dr. Webb on her research and her experiences at Western University.

\section{Tell us a bit about yourself.}

My name is Elizabeth Webb. I completed both my BSc (1994) and PhD (2000) at Western University in Geology and Environmental Science and then went on to a post-doctoral position at McMaster University (2003). I am now an associate professor in the Department of Earth Sciences and live in London with my husband, our new daughter and one neurotic poodle.

\section{What is your area of study? What specifically are you researching in your lab?}

My field of study is Earth Sciences, which encompasses all natural processes that occur on the Earth. Although I was trained in classic geology, my primary research interest involves understanding how climate and water availability influence plants and vice-versa. We can achieve this by studying the stable isotope signatures of natural materials. Isotopes are atoms of the same element that have different masses. The abundance of heavy (rare) isotopes to light (common) isotopes in most materials will vary with the conditions of their formation. Plants contribute many things to our soils including biologically-precipitated minerals, organic matter and charcoal. By studying the stable-isotope composition of these plant residues, we can gain a better understanding of plant productivity, water use efficiency and climate at the time those plants were growing. This information ultimately increases our ability to understand climate change (e.g. paleoclimate) and ecosystem response to climate change and anthropogenic landscape modifications.

For example, we have collected soils from the rainforests in Belize and Guatemala in areas surrounding ancient Maya settlements. The organic matter in these soils that originates from the rain-forest has a very different stable-carbon isotope signature than the organic matter contributed from maize which was cultivated by the ancient populations. Hence, we are able to distinguish which areas were used for maize agriculture and, in collaboration with archaeologists, we can better understand resource distribution, agricultural economy and sustainability in ancient communities. 
Furthermore, the oxygen-isotope composition of minerals that are deposited in plants (known as phytoliths) can be related to the temperature of plant growth. This provides a paleo-thermometer that allows us to obtain ancient climate information from fossil plant residues in the soils. We are also developing new techniques such as measuring the abundance of specific molecules that contain two heavy isotopes, and silicon isotope analyses. These techniques will shed further light on plant growth behaviour under different climate conditions, such as the timing of mineralization, transpiration rates and nutrient availability.

These systems are complex. My students work on understanding how the combination of fluctuating temperatures, relative humidity and water availability affect the stable isotope compositions of modern plants and their minerals. Once these systems are fully understood we will be able to obtain a clearer picture of how climate affected ancient ecosystem productivity based on the analyses of plant residues preserved in soils and sediments.

\section{Why did you choose the field of earth sciences? What sparked your interest in the field of stable-isotope biogeochemistry?}

When I started my undergraduate degree I was enrolled in the Astronomy program with Geology as an elective course. After my first year, I realized that I preferred the more tangible Earth Sciences - having hands-on experience with samples to study and going on field excursions to learn more about the history of the Earth and environment and the relevance to our lives (e.g. climate change and resource development). After studying classical Geology for 4 years I was given an opportunity to study mineralization in plants using stable isotopes. I found it fascinating to see how biological systems could impact the fate of the same ions and form some of the same minerals I had studied in Geology. Possibly because I don't have any formal training in botany, I find the plant biogeochemical systems challenging and stable isotopes are a powerful tool that have helped me in understanding these processes.

\section{What made you choose Western University as opposed to other academic institutions?}

I initially wanted to return to Western to become a professor because of the great facilities we have here thanks to the tireless work of Dr. Fred Longstaffe who built the Laboratory for Stable Isotope Science (LSIS) over the last two decades. Western was advertising for faculty that would become part of a team of researchers in stable-isotope science - sharing and expanding upon the extensive analytical capabilities at Western. Equipment for stable isotope analyses is expensive and often custom made. Starting my career at a university with a well-equipped laboratory meant that I had access to many machines and techniques that would have otherwise taken years to acquire. Most importantly, however, is the amazing team of people that I work here with at Western that make my job even more enjoyable.

\section{In your opinion, what qualities would make one an excellent researcher?}

I think it is important to be curious and driven to seek out answers. Most research is not about finding easy answers. If the answers to research questions were easy to find then they have probably already been answered. You need to stay curious enough about how the world works that you are willing to put in the hard work to solve complex problems that may not even have tangible solutions. However, while curiosity might drive one to become a researcher and stay a researcher, I think that to be a successful researcher you need to stay connected and engaged with the larger scientific community. Keeping on top of new research and networking with other scientists will open up many new and exciting research opportunities that will not only constantly re-fuel your curiosity but also help secure funding, develop new projects and reap the benefits of good collaborations.

\section{What would you say is the hardest part about being a researcher? And the best part?}

Being a scientist requires many skills beyond what we are traditionally trained for in science. A researcher must be a salesperson to promote their work, be constantly writing grants to fund their research and keep a laboratory running as you would manage a small business in terms of finances, services and employees. The biggest challenge is to meet all of these demands without running out of time to do the actual research that you love. To me, the best part about research is trying to figure out a problem that no one has ever solved before, building customised equipment to analyse things that no one else has ever analysed, and in the end when you are interpreting your results, realizing that you now know things that no one else has known before. It is a great feeling when a research project has turned out really well. 


\section{What advice would you give to an undergraduate student interested in getting involved in research?}

Learn as much as you can and get as much experience as you can while you are here at Western and have access to our vibrant research community and cutting edge research laboratories. Undergraduates can accomplish this by approaching faculty and offering to volunteer in research labs or by participating in the work-study program. By working with a variety of different people and on different research projects you will gain a competitive edge for future projects, choice of thesis supervisors, and good referees for graduate school, scholarship applications and possible connections for future job openings. But more importantly experiencing different kinds of research will help you decide what interests you and what you want to do with your future.

\section{What qualities do you look for in a potential research assistant?}

I never expect that an undergraduate research assistant will already have experience working in a stable isotope laboratory as our facility is quite unique. Hence, we provide full training to all incoming students - with the intention to both to educate students and protect our expensive equipment! I personally train most of my assistants because it is important for them to know how to do things and also for them to understand how the techniques were developed and why we have chosen a particular technique. Because training is a significant time investment, I look for assistants that 1) are eager to learn, 2) will be able to advance their career/degree with training in stable isotope science, and 3) will be available to work multiple terms or years so that we can continue to benefit from the skills they have developed. New assistants often begin their training with tedious, repetitive tasks (e.g. grinding or weighing samples), so it is also important to find someone that is detailed oriented, patient and sociable enough that they will interact with other people in the lab even if they are doing solitary work.

\section{What do you believe will be the future of research in stable-isotope science?}

There are currently two contrasting trends in stable-isotope science. New cutting-edge and expensive instruments have increased sensitivity for very precise analysis of smaller samples, individual molecular compounds, or very rare isotopologues which allows researchers to investigate very detailed processes occurring within larger systems. These measurements are incredibly intensive in terms of skill and labour and usually involve precious samples and small data sets (e.g. meteorites, archeological artefacts). In contrast other manufacturers have recently developed instruments that can provide fast isotope analyses with reduced analytical sensitivity at a fraction ( $1 \%)$ of the cost of more traditional isotope-ratio mass spectrometers. These cheaper instruments are becoming widely available, expanding the accessibility of stable isotope analyses to researchers in a wide variety of fields and allowing for the fast collection of large data sets typically required for understanding ecosystem dynamics (rain water, soil organic matter, feathers). Both trends will result in stable-isotopes being used widely as a tool to study any natural system or process on both large and small scales. I think that students in almost any field of science will eventually be reading about or learning these techniques.

To read more on Dr. Webb's research, please visit her website at:

http://www.uwo.ca/earth/people/faculty/webb.htmI 